Cell Research, (2001); 11(1):81-84

\title{
Melanocortin-1 receptor gene variants in four Chinese ethnic populations
}

\author{
SHI Peng, Xue Mei LU, Huai Rong LUO, Jin-Gong XIANG-YU, Y A $_{\text {Ing ZHANG* }}$ \\ Laboratory of Cellular and Molecular Evolution, Kunming Institute of Zoology, the Chinese Academy of \\ Sciences, Kunming 650223, China
}

\begin{abstract}
There is strong relationship between melanocortin-1 receptor (MC1R) gene variants and human hair color and skin type. Based on a sequencing study of MC1R gene in 50 individuals from the Uygur, Tibetan, Wa and Dai ethnic populations, we discuss the occurrence of $7 \mathrm{mc} 1 \mathrm{r}$ variants consisting of 5 nonsynonymous sites (Val60Leu, Arg67Gln, Val92Met, Arg163Gln and Ala299Val) and 2 synonymous sites (C414T and A942G), among which C414T and Ala299Val were reported for the first time. Confirmation and analysis were also made of 122 individuals at three common point mutations (Val92Met, Arg163Gln, A942G) using PCR-SSCP. The frequency of Arg163Gln variant varies in the four ethnic populations, with percentage of $40 \%, 85.0 \%, 66.2 \%$ and $72.7 \%$, respectively, while those of Val92Met and A942G are roughly similar in these four populations. The different environments, migration and admixture of various ethnic groups in China might have impact on the observed frequency of Arg163Gln.
\end{abstract}

Key words: MC1R gene, ethnic populations, nonsynonymous site, synonymous site.

\section{INTRODUCTION}

The variation in human hair and skin color in different geographic regions of the world is the result of differences in two principal forms of melanin, the red-yellow phaeomelanins and the black-brown eumelanins, which are present in the epidermal layer of human skin and hair[1],[2]. The type of melanin produced is under the control of two genes, identified initially by the mouse mutation, extension and agouti. The extension gene is expressed in melanocytes, producing the melanocyte stimulating hormone receptor (MSHR) or melanocortin-1 receptor ( MC1R)[3],[4]. The human MC1R gene, homologous to the mouse extension locus, was cloned[3],[5],[6], located to chromosome 16q24[7] and shown to encode the MC1R protein. Expressed on cutaneous melanocytes[3], MC1R is a seven transmembrane domain G protein-coupled receptor of 317 amino acids belong-

\footnotetext{
* Corresponding author: Ya Ping ZHANG, Tel: 0871-5198993

Fax: 0871-5195430, E-mail: zhangyp@public.km.yn.cn
}

ing to the melanocotin receptor subfamily and has high binding affinity for MSH and ACTH[8, 9]. In addition, some other studies show that MC1R variants are associated with the coat colors in cattle [10],[11], fox[12], and horse[13].

Studies of MC1R polymorphism have been made in European, African and Asian populations. Valverde et al[14], Box et al[15] and Smith et al [16] reported 18 variants of MC1R in red hair/fair skin individuals. In a recent study by Rana et al [4], Africans were reported to be lack of variation while six variants were found in Asian populations. However, little is known about the variants of MC1R gene in Chinese populations, let alone data in Chinese ethnic populations. In this paper we examined the polymorphism of the human MC1R gene in four Chinese ethnic populations.

\section{SAMPLES AND METHODS}

\section{Human samples}

A total of 122 individuals from 4 Chinese ethnic populations (35 Uygur from Xinjiang Province, 20 Tibetans from Qinghai 
$\mathrm{MC1R}$ variants in Chinese ethnic populations

Province, 34 Was and 33 Dais from Yunnan Province.) volunteered as samples for the study. Genetically, none of them was known to be related to any other volunteer and all of their parents and grandparents were descendants of the mentioned nationality.

\section{Amplification and sequencing}

Genomic DNA from blood was amplified by PCR to obtain the entire coding region of human MC1R gene according to Rana et al[4]. PCR products were purified with gel extraction kits (Watson BioMedicals, Inc.) and sequenced with an Applied Biosystem ABI 377 sequencer (PE Biosystems) using BigDye ${ }^{T M}$ Terminator Cycle Sequencing Kit (Perkin-Elmer) under the manufacturer's instructions.

\section{Identification of variants}

Both sequencing and SSCP (single-strand conformation polymorphism) analysis were used to identify the MC1R variants. In our preliminary study, 10 Dais, 15 Tibetans, 15 Uygurs and 10 Was were sampled randomly for sequencing. Three variants (Val92Met, Arg163Gln and A942G) were chosen for PCR-SSCP analysis and gene frequency calculation in 122 individuals. PCRSSCP was performed with three sets of primers to yield three 200-300bp products using the method in reference[17].

\section{Calculation of allele frequency}

The mathematical equations of the allele frequencies and the genotype are given by:

$\mathrm{p}=(2 \mathrm{NAA}+\mathrm{NAa}) / 2 \mathrm{~N} \mathrm{q}=(2 \mathrm{Naa}+\mathrm{NAa}) / 2 \mathrm{~N}$.

In which $p$ and $q$ are the allele frequencies of $\mathrm{A}$ and $\mathrm{a}$; NAA, NAa and Naa are the numbers of AA (wild-genotype), Aa (heterozygous variant-genotype) and aa (homozygous variantgenotype).

\section{RESULTS}

\section{$M C 1 R$ variants}

The entire coding sequence of the MC1R gene was sequenced in 50 individuals from the Urgur, Tibeten, Dai, and Wa nationalities. Compared to the published sequences[3-6], [18], sequences of our samples differed from the human consensus sequence at five nonsynonymous sites (at codon $60,67,92,163$ and 299) and at two synonymous sites (at nucleotide 414 and 942) (Tab 1). In the previous study of MC1R variants, Val92Met and Val60Leu were reported to be frequent in the red hair/fair skin samples[14]. In this study, heterozygous Val60Leu was found only in one Uygur individual; whereas the Val92Met variant was found in Uygur, Dai, Wa ethnic populations, but no homozygote in Tibetan. Furthermore, the Val92Met variant always went with the A942G variant in our samples.
Tab 1. Variants and their regions located in humanMC1R detected in four ethnic population

\begin{tabular}{lll}
\hline Region of human MC1R & \multicolumn{2}{c}{ Variants } \\
\hline First transmembrane region & Val60Leu & (G178T) \\
First intracellular region & Arg67Gln & $(\mathrm{G} 200 \mathrm{~A})$ \\
Second transmembrane region & Val92 Met & $(\mathrm{G} 274 \mathrm{~A})$ \\
Third transmembrane region & Ile138Ile & $(\mathrm{C} 414 \mathrm{~T})$ \\
Second intracellular region & Arg163Gln & $(\mathrm{G} 488 \mathrm{~A})$ \\
Seventh transmembrane region & Ala299Val & $(\mathrm{C} 896 \mathrm{~T})$ \\
Fourth intracellular region & Thr314Thr & $(\mathrm{A} 942 \mathrm{G})$ \\
\hline
\end{tabular}

The variants are indicated by an amino acid and nucleotide change, as well as the codon and nucleotide position compared with the human consensus sequence.

Tab 2. Variant frequencies within four ethnic groups

\begin{tabular}{|c|c|c|c|c|c|c|c|}
\hline \multirow{2}{*}{$\begin{array}{l}\text { Ethnic } \\
\text { group }\end{array}$} & \multirow[b]{2}{*}{$\mathrm{n}$} & \multirow[b]{2}{*}{ Variant allele } & \multicolumn{3}{|c|}{ Genotype $^{a}$} & \multicolumn{2}{|c|}{ Allele frequencyb } \\
\hline & & & $\mathrm{AA}$ & $\mathrm{Aa}$ & aa & $\mathrm{p}$ & $q$ \\
\hline \multirow{3}{*}{ Tibetan } & \multirow{3}{*}{20} & Val92Met & 16 & 4 & 0 & 0.9000 & 0.1000 \\
\hline & & Arg163Gln & 1 & 4 & 15 & 0.1500 & 0.8500 \\
\hline & & A942 & 16 & 4 & 0 & 0.9000 & 0.1000 \\
\hline \multirow{3}{*}{ Uygur } & \multirow{3}{*}{35} & Val92Met & 29 & 4 & 2 & 0.8857 & 0.1143 \\
\hline & & Arg163Gln & 14 & 14 & 7 & 0.6000 & 0.4000 \\
\hline & & A942G & 27 & 6 & 2 & 0.8571 & 0.1429 \\
\hline \multirow{3}{*}{ Dai } & \multirow{3}{*}{33} & Val92Met & 15 & 15 & 3 & 0.6818 & 0.3182 \\
\hline & & Arg163Gln & 6 & 6 & 21 & 0.2728 & 0.7272 \\
\hline & & A942G & 15 & 15 & 3 & 0.6818 & 0.3182 \\
\hline \multirow{3}{*}{ Wa } & \multirow{3}{*}{34} & Val92Met & 27 & 6 & 1 & 0.8824 & 0.1176 \\
\hline & & Arg163Gln & 5 & 13 & 16 & 0.3382 & 0.6618 \\
\hline & & A942G & 26 & 7 & 1 & 0.8676 & 0.1324 \\
\hline
\end{tabular}

揟he number of individual alleles genotype: $\mathrm{AA}=$ homozy- gous wild-type, $\mathrm{Aa}=$ heterozygous variant, aa=homozygous variant.

${ }^{b} p$ represents the frequency of the A allele; $q$ represents the frequency of the a allele?

Rana et al[4] reported the Arg163Gln variant to be associated with the East and Southeast Asian populations. In this study, a very common Arg163Gln variant was also found in the four ethnic groups concerned, including 21 of 35 Uygurs, 19 of 20 Tibetans, 29 of 34 Was and 27 of 33 Dais. The Arg67Gln/Arg163 variant in one Dai individual was also observed in other East and Southeast Asian populations (Rana et al, 1999), which is a combination of the Arg163Gln variant. Besides,

one synonymous mutation and one nonsynonymous mutation were first found in Uygur (C414T and Ala299Val).

\section{Gene frequency}

The PCR-SSCP analysis was used to genotype the three variants, Val92Met, Arg163Gln and 
A942G in 122 individuals. The gene frequency of the Arg163Gln variant was found to be significantly different in the four ethnic groups, with the highest $(85.0 \%)$ in Tibetan, the lowest (40\%) in Uygur, and the intermediate in Dai $(72.7 \%)$ and $\mathrm{Wa}(66$. $2 \%)$. The gene frequency of the Val92Met differed in the Dai (31. 8\%), the Tibetans (10\%), the Wa (11.8\%) and the Uygur (11.4\%). The A942G and Val92Met variant gene frequency for each of the four ethnic groups remained roughly similar, as listed in Tab 2. Hardy-Weinberg equilibrium was not rejected in all these ethnic groups (Data not shown).

\section{DISCUSSION}

$\mathrm{MC} 1 \mathrm{R}$ is a regulator of eumelanin and phaeomelanin production, and its mutations might cause the changes in human hair and skin color[1], [2].

Three alleles (Arg151Cys, Arg160Trp and Asp294His) that are associated with red hair/fair skin phenotype have been reported in European individuals[5],[16]. Recently, Franderberg et al[19] found new evidence that the Arg151Cys mutation of MC1R can cause the synthesis of the red pigment. This evidence explains why the red hair person carries the Arg151Cys mutation. The Arg163Gln variant is present with relatively high frequency in the East and Southeast Asian populations[4],[20]. In consistent with those reports, our result shows a very common Arg163Gln variant in the four ethnic groups. It might suggest that the Arg163Gln polymorphism is associated with phaemomelanin-rich skin. But further functional study is required to confirm our expectation.

The Arg163Gln variant is found in American Indians as well as in East and Southeast Asian populations, while the allele appears at a very low frequency or even disappears in both Europeans and Africans. Rana et al[4] considered that the allele has increased rapidly in frequency in East Asians by positive Darwinian selection. We suggest that the random genetic drift, migration and the admixture of various ethnic groups might have impact on the frequency of the Arg163Gln variant in different populations. Firstly, the highest frequency and the most homozygous state in Tibetans might arise from genetic drift and little possibility of gene flows among different ethnic groups. The positive
Darwinian selection is also a possible explanation. Secondly, the lowest frequency in Uygurs might be the result of their genetic admixture with Caucasians. This assumption can be further supported by results from other reports[17],[22]. On the other hand, considering the genetic admixture, it is explicable that an European specific allele, Val60Leu, is present in one Uygur individual. Lastly, the similar frequencies in the Dai and the Wa might be explained by their similar geographic locations and living environments.

Tab 2 shows that the gene frequency of A942G in the Dai and the Wa originating in southern China is $20 \%$ and the frequency in the Tibetan and the Uygur is $10 \%$ and $12 \%$, respectively; whereas Rana et al[4] reported a $42 \%$ gene frequency in the Africans, 23\% in east and southeast Asians and the absence in American Indians. It seems that the gene frequency of A942G decreases with increasing latitude. Nevertheless, more data are needed to examine this possibility.

In addition to the three variants (Val92Met, Arg163Gln and A942G), two new mutations are found in two Uygur individuals, one with C414T in homozygous state and the other with Ala299Val in heterozygous state. The occurrence of two new mutations and the question whether the differences can suggest the genetic divergences in these four ethnic groups or not, require further investigation.

\section{ACKNOWLEDGMENTS}

We are grateful to Prof. Wen Hsiung LI for his constructive suggestions; to Yong Gang YAO for discussion; to Prof. JL REES for help. This work was supported by Natural Sciences Foundation of China, the Chinese Academy of Sciences and NSF of Yunnan Province to Ya Ping ZHANG.

\section{REFERENCES}

[1] Thody AJ, Higgins EM, Wakamatsu Ket al. Phaeomelanin as well as eumelani is present in human epidermis. $J$ Invest Dermator 1991; 97:340-4.

[2] Prota G. Recent advance in the chemistry of melanogenesis in mammals. J Invest Dermatol 1980; 75:122-7.

[3] Mountjoy KG, Robbins LS, MT Nortrud, Cone RD. The cloning of a family of genes that encode the melanocortin receptors. Science 1992; 257:1248-51.

[4] Rana BK, Hewett- Emmett D, Jin L et al. High polymorphism at the human melanocortin 1 receptor locus. Genetics 1999; 151:1547-7. 
[5] Chhajlani V, Wiaberg JES. Molecular cloning and expression of the human melanocyte stimulating hormone receptor cDNA. FEBS Lett 1992; 309:417-20.

[6] Gantz I, Konda Y, Tashiro T et al. Molecular cloning of a novel melanocortin receptor. J Biol Chem 1993; 268: 8246-50.

[7] Magenis RE, Smith L, Nadeau JH et al. Mapping of the ACTH, MSH, and neural (MC3 and MC4) melanocortin receptors in the mouse and human. Mamm Genome 1994; 5:503-8.

[8] Robbins LS, Nadeau JH, Johnson KR et al. Pigmentation phenotypes of variant extension locus alleles result from point mutations that alter MSH receptor function.Cell 1993; 72:827-34.

[9] Mountjoy KG. The human melanocyte stimulating hormone receptor has evolved to become "super-sensitive" to melanocortin peptides. Mol Cell Endocrinol 1994; 102:R7-11.

[10] Klungland H, Vieira WD, Gomez-Raya L, Adalsteinsson $\mathrm{S}$, Lien S. The role of melanocyte stimulating hormone (MSH) receptor in bovine coat color determination. Mamm Genome 1995; 6:636-9.

[11] Joerg H, Fries HR, E Meijernik, Stranzinger GF. Red coat color in holstein cattle is associated with a deletion in the MSHR gene. Mamm Genome 1996; 7:317-9.

[12] Vage DG, Lu D, Klungland $\mathrm{H}$ et al. A non-epistatic interaction of agouti and extension in the fox, Vulpes vulpes. Nat Genet 1997; 15:311-5.

[13] Johansson M, Marklund L, Sandber GK, Andersson L. Cosegregation between the chestnut coat colour in horses and polymorphisms at the melanocyte-stumulation hormone (MSH) receptor locus. Anim Genet 1994; 25:35.

[14] Valverde P, Healy E, Jackson I, Rees JL, Thody AJ. Variants of the melanocyte stimulating hormone recep- tor gene are associated with red hair and fair skin in humans. Nat Genet 1995; 11:328-30.

[15] Box NF, Wyeth JR, O'Gorman LE et al. Characterization of melanocye stimulating hormone receptor variant alleles in twins with red hair. Hum Mol Genet 1997; 11: 1891-7.

[16] Smith R, Healy E, Siddiqui S et al. Melanocortin 1 receptor variants in an Irish population. J Invest Dermatology 1998; 111:119-22.

[17] Yao Y-G, LU X-M, Luo H-R, Li W-H, Zhang Y-P. Gene admixture in the Silk Road region of China -evidence from mtDNA and melanocortin 1 receptor polymorphism. Genes and Genetic Systems 2000; 75: 173-8.

[18] Cone RD, Lu D, Koppula S et al. The melanocortin receptors: agonsis, antaagonista, and the hormonal control of pigmentation. Recent Prog Horm Res 1996; 51 : 287-318.

[19] Frandberg PA, Doufexis M, Kapas S, et al. Human pigmentation phenotype: a point mutation generates nonfunctional MSH receptor. Biochem Biophys Res Commun 1998; 245:490-2.

[20] Harding RM, Healy E, Ray AJ et al. Evidence for variable selective pressures at MC1R . Am J Hum Genet 2000; 66: 1351-61.

[21] Cavalli-Sforz LL, Menozzi P, Piazza A. In: The History and Geography of Human Genes. Princeton University Press: Princeton 1994:304-8.

[22] Chen RB, Ye GY, Geng, ZC et al. Revelation of the origin of Chinese nation from clustering analysis and frequency distribution of HLA polymorphism in major minority nationalities in mainland China. Acta Genetica Sinica 1993; 20(5):389-93. 